\title{
Li-Fi: Wireless Communication Media
}

\author{
Prof. Amit K. Mishra ${ }^{1}$, Mr. Lalit A. Pawar ${ }^{2}$, Mr. Sandeep U. Gaikwad ${ }^{3}$, Mr. Gaurav A. Sonawane \\ Department of Electronics \&Telecommunication, SIEM, Nasik, India ${ }^{1,2,3,4}$
}

\begin{abstract}
Simply, Li-Fi is nothing but Wi-Fi using light. By using light data can transmit. German physic DR. HARALD HASS was invented Light Fidelity (Li-FI) Technology. This is very much latest technology in which light emitting diode can transmit data much faster and flexible as compare to Wi-Fi technology. Here we develop the application module of Li-Fi technology. In which data can transmit through LED and receive by using photo diode.
\end{abstract}

Keywords: Li-Fi, Wi-Fi, LED, ATMEGA328.

\section{INTRODUCTION}

The aim of this project is to make system for data transfer in indoor unit.For wireless communication we use radio and microwave which is done by electromagnetic spectrum.The radio waves are limited in range. When number of users are more RF spectrum is over loaded due to which electromagnetic spectrum is affected.Hence reduction occurs in efficiency of system.German physic 'Harald Hass'has define the data can transmit by illumination.Data can be send by using fiber optic through an LED light bulb with varies intensity which is faster than human eye follow.If LED bulb is in ON state, it transmit the digital 1 and if in OFF state transmit digital $0 . I t$ can proceed very fastly as light will ON and OFF quickly.Data will be encode in light by varying the rate of flickering period $\mathrm{ON}$ and $\mathrm{OFF}$ of LED light.It gives different string of 1 's and 0 's.The medium use for transmitting data is visible light spectrum through LED.LiFi is very faster,secure and cheaper in cost as campare to Wi-Fi or any other wireless transmission.

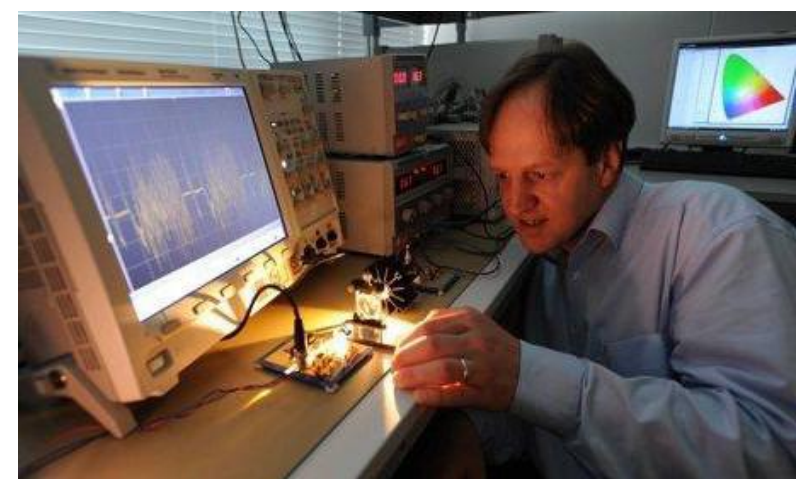

Fig.1. Harald Hass

\section{LITERATURE SURVEY}

In Wi-Fi technology user depends upon the source like routers but in case of $\mathrm{Li}-\mathrm{Fi}$ it is not. The $\mathrm{Li}-\mathrm{Fi}$ technology uses light as a source for data transfer while Wi-Fi uses a radio signal which is unable to use underwater for data transmission. We know light can pass through water, hence Li-Fi is helpful for underwater data transmission. In Wi-Fi technology data can easily hacked because of radio waves can penetrate through the walls but in case of Li-Fi data are more secured as light cannot penetrate through the walls.
TABLE I Comparison of Li-Fi and Wi-Fi

\begin{tabular}{|l|l|l|}
\hline Parameters & Li-Fi & Wi-Fi \\
\hline $\begin{array}{l}\text { Operating } \\
\text { band }\end{array}$ & $\begin{array}{l}\text { Visible Light } \\
\text { band }\end{array}$ & $\begin{array}{l}\text { Radio frequency } \\
\text { band }\end{array}$ \\
\hline Range & $\begin{array}{l}\text { Based on LED } \\
\text { light intensity }\end{array}$ & About 100m \\
\hline Frequency & $\begin{array}{l}4-8^{x} 1014 \mathrm{~Hz} \\
\text { (Visible light) }\end{array}$ & $4-5 \mathrm{GHz}$ \\
\hline $\begin{array}{l}\text { Data transfer } \\
\text { rate }\end{array}$ & $>1 \mathrm{Gbps}$ & $\begin{array}{l}\text { Downlink } \\
\text { speed:10.9Mbps } \\
\text { Uplink Speed: } \\
2.8 \mathrm{Mbps}\end{array}$ \\
\hline $\begin{array}{l}\text { Power } \\
\text { consumption }\end{array}$ & Medium & Medium \\
\hline Standard & IEEE 802.15 & IEEE $802.11 \mathrm{~b}$ \\
\hline Cost & Low & High \\
\hline Security & Highly secured & Less secure \\
\hline
\end{tabular}

\section{SYSTEM ARCHITECTURE}

Our system is divided in two sections transmitter section and receiver section as shown in block diagram.

A. Transmitter Section

Transmitter section consists of microcontroller ATMEGA328 in which programming using AVR studio5 is done. Temperature sensor is use to measure temperature while Gas sensor is use to sense smoke. The measure data of sensors are store in ATMEGA328.This data is been transfer using LED panel by light waves. When LED is ON microchip convert digital data in form of light. The operational procedure is simple. If the LED is on, we transmit a digital 1 and if it is off transmit a 0 . The LED can be switched on and off very quickly, which gives nice opportunities for transmitting data.

\section{B. Receiver Section}

Receiver section consists of photo detector, which detects the light. Then this light is amplified and fed to the device driver. Using this device driver we drive the receive data to the ATMEGA328, which stores this data and display on LCD Display in receiver section. 


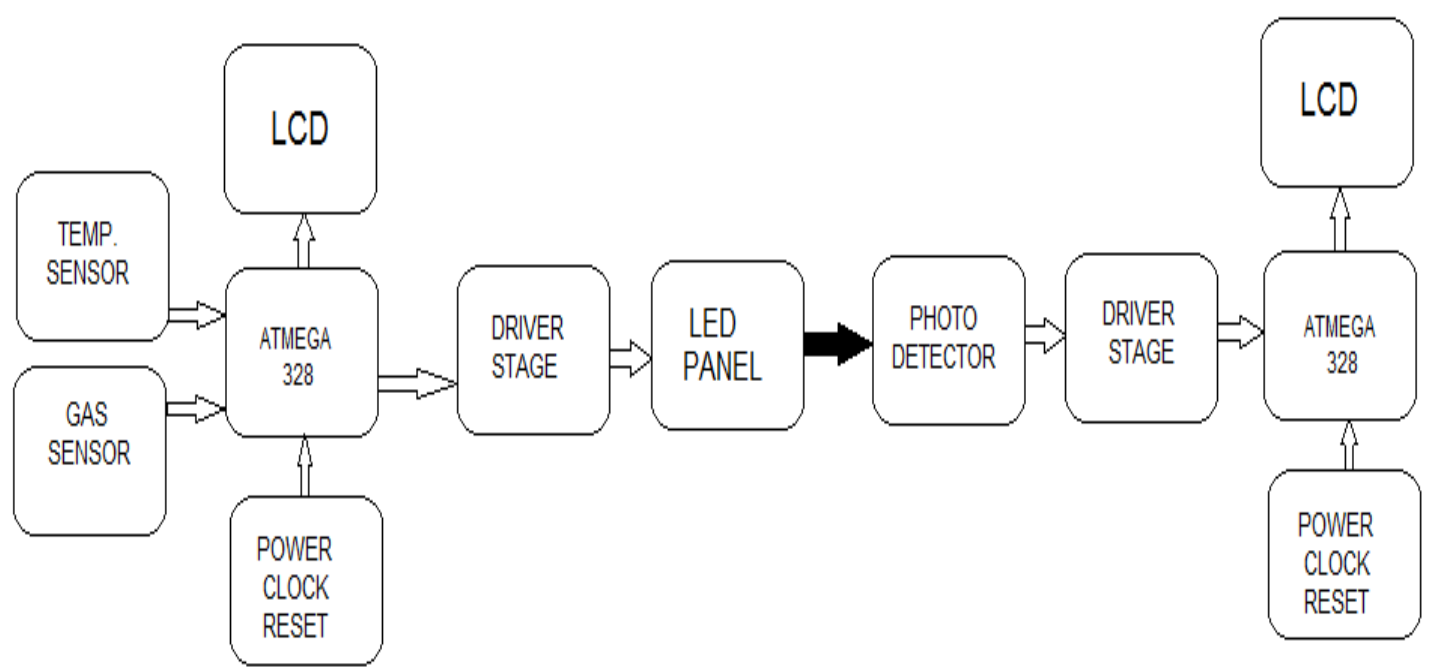

Fig2. Block Diagram

\section{FLOW CHART}

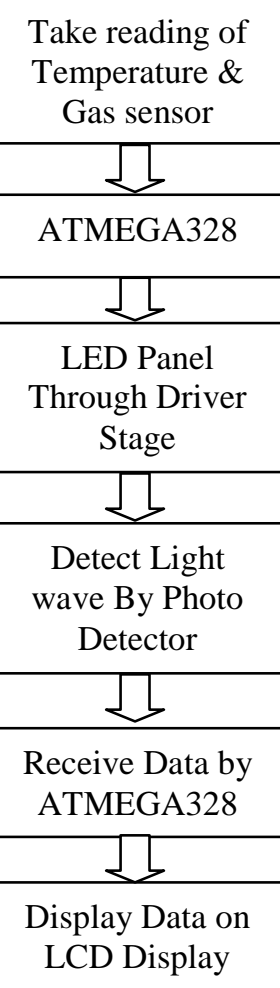

Fig.3. Flow Chart

\section{PERFORMANCE ANALYSIS}

A. Circuit Diagram of Transmitter Section

In Transmitter section we use Micro Controller IC ATMEGA328 in which coding by using $\mathrm{C}$ language is done. LCD, Temperature sensor and Gas sensor are interface with controller IC. The Sensing results are stored in an IC and display on LCD in transmitter side. This stored Data is been transmitted by using LED panel.

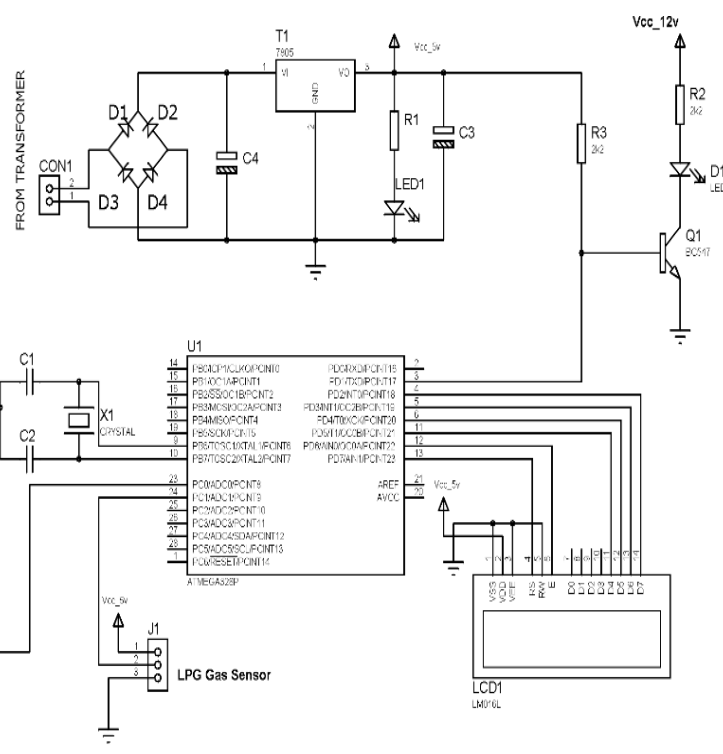

Fig4. Transmitter Circuit

B. Circuit Diagram of Receiver Section

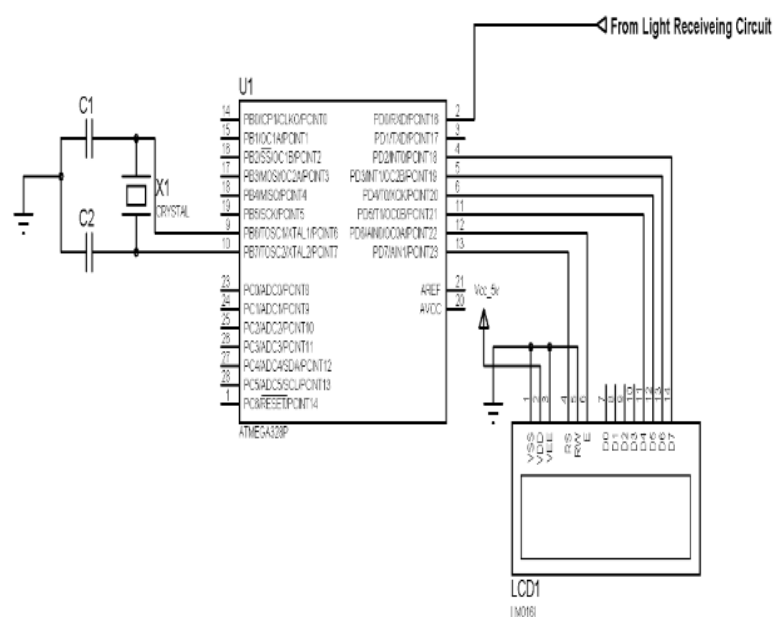

Fig.5. Receiver Circuit 
In receiver we use microcontroller IC ATMEGA328. LCD Display is interface with controller IC. By using Photo detector light can be detected, this light is amplified and fed to driver. Then Device Driver can drive the receive data to ATMEGA328 which is displaying on LCD as a result.

\section{ADVANTAGES AND APPLICATION'S OF LI-FI}

- Use in Aircraft

- Li-Fi uses light rather than radio frequency

- High speed

- Integrated into medical devices and in hospitals as it does not use radio waves.

- As Under water in sea Wi-Fi does not work, Li-Fi is useful

- Security is the Advantage as light does not penetrate through walls

- $\mathrm{Li}-\mathrm{Fi}$ solve the issue as shortage range of radio frequency bandwidth

\section{LIMITATION}

- It can only transmit when in the line of sight and does not pass through obstacle.

\section{CONCLUSION}

In this study we implement a system which gives the application model of Li-Fi Technology. It uses the visible light spectrum which is better than Radio frequency spectrum. With the use of LED data can transmit at very high speed. If this technology can be put in practical, every LED bulb can be used as like Wi-Fi hotspot to transmit data more secure and safe.

\section{ACKNOWLEDGMENT}

We would like to express profound gratitude to Dr. R. G. Tated (Principal, SIEM Nasik) for his valuable support, encouragement, supervision and useful suggestions throughout this work. Also to Prof. D. P. Patil, Prof. B. D. Deore, Prof. P. P. Chaudhary and Prof. K. B. Jagtap of Department of Electronics \& Telecommunication for Moral support and continuous guidance enabled us to complete this work successfully.

\section{REFERENCES}

[1] N.S.Jaiswal and P.S. Chopde, "Review of Li-Fi Technology: New Future Technology-Light Bulb to Access the Internet!", International Journal of Scientific \& Engineering Research, Volume 4, Issue 12,December-2013

[2] M. Mutthamma, "A survey on Transmission of data through illumination-Li-Fi", International Journal of Research in Computer and Communication Technology, Vol 2, Issue 12, December-2013

[3] S.K. Binu Siva Singh, S. Vignesh, M. Athiban MahaMathi," A survey on methodologies for LI-FI (Light Fidility) technology", Journal of Chemical and Pharmaceutical Sciences, ISSN:0974-2115

[4] D. Jadhav, S. Patil, R. Singh and K. Patel, "Lifi(Light fidility)Efficient use of visible spectrum", International Journal of Engineering Science Invention, Volume 4 Issue 3, March 2015, PP $77-81$

[5] http://en.wikipedia.org/wiki/Li-Fi

[6] Seminarprojects.com/s/seminar-report-on-lifi

[7] www.lificonsortium.org/
[8] Esha Jalka, Deepak Kumar, "A Review Paper On Li-Fi Technology", International Journal of scientific \& Engineering Research, Volume 6, Issue 2, February-2015.

\section{BIOGRAPHIES}

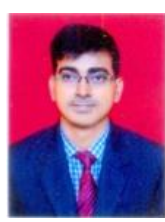

Prof. Amit K. Mishra - Received BE From SSEC Bhavnagar Gujrat and ME in Communication from MIT Aurangabad. Have 8 Publications in various international and national Journal and Conferences. Presently working as a Assistant Professor in department of Electronics and Telecommunication Engineering of sandip foundation's SIEM, Nasik.

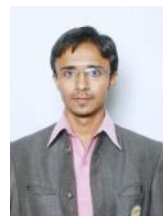

Mr. Lalit A. Pawar - Pursuing BE in Electronics and Telecommunication engineering from department of Electronics and Communication Engineering of sandip foundation's SIEM, Nasik.

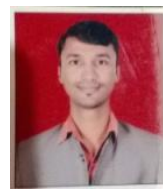

Mr. Sandeep U. Gaikwad - Pursuing BE in Electronics and Telecommunication engineering from department of Electronics and Communication Engineering of Sandip foundation's SIEM, Nasik.

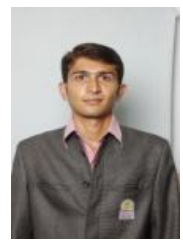

Mr. Gaurav A. Sonawane - Pursuing BE in Electronics and Telecommunication engineering from department of Electronics and Communication Engineering of Sandip foundation's SIEM, Nasik. 